\title{
Management of Acute Ischemic Stroke
}

\author{
Ponniah Vanamoorthy ${ }^{1}$ Kavu D. Samy ${ }^{1}$ Prasanna U. Bidkar ${ }^{2}$ \\ ${ }^{1}$ Department of Neuroanaesthesiology and Neurocritical Care, \\ Institute of Neurosciences and Spinal Disorders, MGM Health Care, \\ Chennai, Tamil Nadu, India \\ 2Division of Neuroanaesthesiology, Department of Anaesthesiology \\ and Critical Care, Jawaharlal Institute of Postgraduate Medical \\ Education \& Research (JIPMER), Puducherry, India
}

\begin{abstract}
Address for correspondence Ponniah Vanamoorthy, MBBS, MD (Anaesthesiology), Neuroanesthesiology and Neurocritical Care, Institute of Neurosciences and Spinal Disorders, MGM Health Care, Chennai 600030, Tamil Nadu, India (e-mail: drponns@gmail.com).
\end{abstract}

J Neuroanaesthesiol Crit Care 2019;6:105-118

\begin{abstract}
Keywords

- stroke

- acute ischemic stroke

- intravenous

thrombolysis

- telestroke

- CT perfusion

Acute ischemic stroke (AIS) is a time-sensitive neurological emergency and it remains to be the most common type of stroke. Rapid neuroimaging is the cornerstone for initiating time-sensitive interventions in the treatment of AIS. Revascularization therapies that were once considered irreversible, including intravenous thrombolysis (IVT) and endovascular treatment (EVT), administered in a timely fashion have revolutionized the treatment of AIS. The indications for these therapies have expanded over the past few years and a lot of advancements are happening every year. IVT is offered to all eligible patients presenting within 3 hours of symptom onset and up to 4.5 hours with additional criteria. EVT with stent retrievers or aspiration devices, once limited to the first 6 hours of stroke onset, is now being offered up to 24 hours with advanced image-guided patient selection, which includes a computed tomography or magnetic resonance perfusion imaging. A protocol-based approach to the management of stroke, beginning from prehospital care reduces the time delay in the initiation of treatment. Providing access to these therapies by creating systems of care, hospital stroke team, and "stroke codes" improves the outcome of patients with AIS.
\end{abstract}

\section{Introduction}

Stroke is the second leading cause of death worldwide next to ischemic heart disease. ${ }^{1}$ There are over 13.7 million new strokes each year, and ischemic stroke remains to be the most common type with 9.5 million new cases. ${ }^{2}$ There are 67.5 million ischemic stroke survivors worldwide and 2.7 million deaths occur from ischemic stroke. Every year, 51.9 million healthy lives are lost due to ischemic stroke-related death and disability. Most strokes occur in age group greater than 44 years, but stroke is also common in young generation ( $7 \%$ of new ischemic stroke and $10 \%$ of survivors are under the age of 44 years). Men and women are more or less equally affected (52\% of new cases of stroke occur in men vs. $48 \%$ in women). ${ }^{3.4}$ The conventional risk factors for the development of stroke are hypertension, diabetes mellitus, hyperlipidemia, smoking, obesity, and sedentary lifestyle. ${ }^{5}$ Great progress has been made in the treatment of ischemic stroke with the evolution of intravenous thrombolysis (IVT) and endovascular treatment (EVT). For these treatments to be effective, they should be initiated early from the time of symptom onset. This is possible only by having systems of care and coordination between the specialties. In a typical large vessel occlusion (LVO) about 1.9 million neurons, 14 million synapses, $12 \mathrm{~km}$ of myelinated fibers are lost each minute without revascularization. ${ }^{6}$ This signifies "Time is brain" and time lost is brain lost. Delay in initiating emergent revascularization therapies will result in worst outcomes.

\section{Identification of Stroke}

Stroke can occur in the community or in the hospital. The first responders in the community are usually the family members, the paramedics, or a nursing home practitioner. Stroke is recognized by the following acronym BEFAST.?

\section{received}

March 7, 2019

accepted after revision

May 12, 2019
DOI https://doi.org/

10.1055/s-0039-1692831

ISSN 2348-0548.
Copyright $\odot 2019$ Indian Society of Neuroanaesthesiology and Critical Care
License terms

() (1) $\ominus \circledast$ 
- Balance-Acute or sudden onset of loss of balance or co-ordination

- Eye signs-Blurred or unclear vision/double vision/gaze preference

- Facial weakness-Facial asymmetry

- Arm and/or leg weakness

- Speech difficulty/slurring of speech

- Time is brain-Time to activate stroke system and stroke clock

Stroke is a clinical diagnosis, and rapid neuroimaging, usually a non-contrast computed tomography (NCCT) head is performed to rule out a hemorrhage and to initiate time-sensitive interventions. Ischemic stroke is caused by abrupt and sustained reduction in regional cerebral blood flow (CBF) leading to cell death. Within hours, patients often have a central zone of irreversibly damaged tissue destined to die, known as the infarct core and a surrounding zone of damaged tissue that may recover with abrupt restoration of CBF known as penumbra. Secondary stroke prevention targets a variety of mechanisms, including cardiac embolism, artery to artery thromboembolism, occlusive arterial disease, and small vessel disease that caused acute ischemic stroke (AIS). However, detailed mechanism of AIS is not necessarily relevant to the choice of acute treatment.

\section{Prehospital Management}

Stroke centers with trained paramedics can easily recognize a stroke and they play a vital role in the stroke system of care in reducing the time delay to administer therapies. The key information that the paramedical team conveys to the stroke center are the time of onset of symptoms or the time last seen normal (LSN), blood pressure (BP), and capillary blood glucose (CBG). A prehospital checklist would help decide the in-house stroke team to bypass the emergency room (ER). An awake patient with normal breathing pattern and who is hemodynamically stable with stroke symptoms can be taken directly to CT. Various prehospital scales are being used to identify stroke and LVO. Cincinnati prehospital stroke severity scale is evaluated to have high accuracy in identifying transient ischemic stroke (TIA) and also stroke severity. ${ }^{8,9}$ Noorian et al did a comparative analysis of eight prehospital scales including Los Angeles Motor Scale (LAMS) and concluded that the LAMS performed in the field by paramedics showed good sensitivity and specificity in identifying LVO AIS patients among all cerebral ischemia patients. ${ }^{10}$

Mobile stroke units have the facility to do CT and transfer the image for interpretation to the stroke team and IVT can be initiated in the ambulance. Currently, there is only one mobile stroke unit in India and in future many such would come if found to be cost-effective.

Though guidelines recommend initiating IVT before transferring to EVT facility, ${ }^{11}$ many practitioners favor direct shifting to EVT facility without time delay.

\section{Stroke Team and Stroke Code}

Systems of care have been found to impart positive outcomes in time-sensitive emergencies including trauma, acute coronary syndrome, and stroke. ${ }^{12}$ Depending on the expertise available in a hospital, a stroke team is formed to provide round the clock stroke services. Such team would typically consist of a physician, nursing practitioner, clinical pharmacist, radiographer, technician, laboratory personal, attending staff, social worker, and a manager or counsellor. ${ }^{13}$ Once stroke code gets activated, all team members get together and start evaluating the patient, check eligibility for IVT/EVT, and perform their specific roles.

\section{Emergency Room Assessment and Intervention}

Patients can be shifted in an ambulance stretcher (without a need to change to hospital trolley). Time should not be wasted in changing to hospital clothes. Before shifting to radiology, the key things to be optimized (if compromised) are the airway, breathing, and circulation. Oxygen supplementation should be given through a face mask if peripheral capillary oxygen saturation is less than $94 \% .{ }^{14}$ Most often AIS patients present with hypertension. When the cause for stroke is not clearly known at this stage, it is reasonable to reduce the systolic blood pressure (SBP) to target $185 \mathrm{~mm} \mathrm{Hg}$ as all the stroke patients except for when they present late (out of window period) require BP control to be eligible for revascularization. ${ }^{15}$ Two large bore IV cannulas are to be secured in both arms and a balanced crystalloid infusion initiated at $50 \mathrm{~mL}$ per hour in one line, while the other dedicated for IVT. Simultaneously, blood has to be collected for laboratory testing. Hypotension with SBP $<90 \mathrm{~mm} \mathrm{Hg}$ should be aggressively treated with vasopressors as it is associated with poor outcomes. ${ }^{16}$

Time should not be delayed in detailed history or neurological examination. Serious neurological issues such as raised intracranial pressure and herniation and status epilepticus should be quickly recognized and treated. The National Institute of Health Scale (NIHSS) (-Table 1) is a recognized tool to document and communicate the neurological deficit in the setting of AIS. ${ }^{17}$ The NIHSS ranges from 0 to 42 points with a score of 0 to 5 points suggesting a mild stroke, 6 to 15 a moderate stroke, and greater than 15 a severe stroke.

Apart from establishing the symptom of onset of stroke, a brief medical history including history of medications, particularly the use of anticoagulants, is important in the decision making for treatment. Detailed laboratory tests should not delay neuroimaging. CBG is essential and CBG $<50 \mathrm{mg} / \mathrm{dL}$ has to be corrected with dextrose solution. The platelet count and international normalized ratio should be notified immediately once ready, especially when the patient is on oral anticoagulation. Electrocardiogram, chest X-ray, and ECHO are not warranted unless there is pressing serious coexisting cardiac symptoms.

If the prehospital checklist could be completed and stroke team informed, then ER can be bypassed ${ }^{18}$ and patient shifted 
Table 1 National Institute of Health Stroke Scale

\begin{tabular}{|c|c|c|c|}
\hline Item & Title & Score & NIHSS \\
\hline \multirow[t]{4}{*}{$1 \mathrm{~A}$} & \multirow[t]{4}{*}{ Loss of consciousness } & 0 & Alert-keenly responsive \\
\hline & & 1 & Drowsy-arousable by minor stimulation \\
\hline & & 2 & Stuporous-requires repeated stimulation \\
\hline & & 3 & $\begin{array}{l}\text { Comatose-responds only with reflex motor or autonomic effects } \\
\text { or no response }\end{array}$ \\
\hline \multirow[t]{3}{*}{ 1B } & \multirow{3}{*}{$\begin{array}{l}\text { LOC questions } \\
\text { Ask month and age }\end{array}$} & 0 & Answers both correctly \\
\hline & & 1 & Answers one correctly \\
\hline & & 2 & Both incorrect \\
\hline \multirow[t]{3}{*}{$1 C$} & \multirow{3}{*}{$\begin{array}{l}\text { LOC command } \\
\text { Ask to open and close eyes, grip, } \\
\text { and release of nonparetic hand }\end{array}$} & 0 & Obeys both correctly \\
\hline & & 1 & Obeys one correctly \\
\hline & & 2 & Both incorrectly \\
\hline \multirow[t]{3}{*}{2} & \multirow[t]{3}{*}{ Best gaze } & 0 & Normal \\
\hline & & 1 & Partial gaze palsy-abnormal gaze in one or both eyes \\
\hline & & 2 & Forced deviation or total gaze paresis \\
\hline \multirow[t]{4}{*}{3} & \multirow[t]{4}{*}{ Visual fields } & 0 & No visual loss or in coma \\
\hline & & 1 & Partial hemianopia \\
\hline & & 2 & Complete hemianopia \\
\hline & & 3 & Bilateral hemianopia or cortical blindness \\
\hline \multirow[t]{4}{*}{4} & \multirow[t]{4}{*}{ Facial palsy } & 0 & Normal \\
\hline & & 1 & Minor-flattened nasolabial fold or smiling asymmetry \\
\hline & & 2 & Partial-total or near total paralysis of lower face \\
\hline & & 3 & Complete-absent facial movement \\
\hline \multirow[t]{5}{*}{$5 \mathrm{~A}$} & \multirow[t]{5}{*}{ Best motor RT arm } & 0 & No drift-holds limb at 90 for full $10 \mathrm{~s}$ \\
\hline & & 1 & Drifts down but does not hit bed \\
\hline & & 2 & Some effort against gravity \\
\hline & & 3 & No effort against gravity \\
\hline & & 4 & No movement \\
\hline \multirow[t]{5}{*}{$5 B$} & \multirow[t]{5}{*}{ Best motor LT arm } & 0 & No drift-holds limb at 90 for full $10 \mathrm{~s}$ \\
\hline & & 1 & Drifts down but does not hit bed \\
\hline & & 2 & Some effort against gravity \\
\hline & & 3 & No effort against gravity \\
\hline & & 4 & No movement \\
\hline \multirow[t]{5}{*}{$6 A$} & \multirow[t]{5}{*}{ Best motor RT leg } & 0 & No drift-holds limb at 45 for full $5 \mathrm{~s}$ \\
\hline & & 1 & Drifts down but does not hit bed \\
\hline & & 2 & Some effort against gravity \\
\hline & & 3 & No effort against gravity \\
\hline & & 4 & No movement \\
\hline \multirow[t]{5}{*}{$6 \mathrm{~B}$} & \multirow[t]{5}{*}{ Best motor LT leg } & 0 & No drift-holds limb at 45 for full $5 \mathrm{~s}$ \\
\hline & & 1 & Drifts down but does not hit bed \\
\hline & & 2 & Some effort against gravity \\
\hline & & 3 & No effort against gravity \\
\hline & & 4 & No movement \\
\hline \multirow[t]{3}{*}{7} & \multirow[t]{3}{*}{ Limb ataxia } & 0 & Obeys or absent (coma) \\
\hline & & 1 & Present in one limb \\
\hline & & 2 & Present in two limbs \\
\hline
\end{tabular}


continued

\begin{tabular}{|c|c|c|c|}
\hline Item & Title & Score & NIHSS \\
\hline \multirow[t]{3}{*}{8} & \multirow[t]{3}{*}{ Sensory } & 0 & Normal \\
\hline & & 1 & Partial loss (pin prick is less sharp or dull on affected side) \\
\hline & & 2 & Dense loss or in coma (unaware of touch on face, arm, or leg) \\
\hline \multirow[t]{4}{*}{9} & \multirow[t]{4}{*}{ Best language } & 0 & No aphasia \\
\hline & & 1 & $\begin{array}{l}\text { Mild to moderate (loss of fluency without significant limitation on } \\
\text { ideas expression) }\end{array}$ \\
\hline & & 2 & $\begin{array}{l}\text { Severe (fragmentary expression, need for listener inference or } \\
\text { guessing) }\end{array}$ \\
\hline & & 3 & Mute or in coma (no speech or auditory comprehension) \\
\hline \multirow[t]{3}{*}{10} & \multirow[t]{3}{*}{ Dysarthria } & 0 & Normal \\
\hline & & 1 & $\begin{array}{l}\text { Mild to moderate (slurs, some words can be understood with } \\
\text { some difficulty) }\end{array}$ \\
\hline & & 2 & $\begin{array}{l}\text { Unintelligible or worse (so slurred speech, out of proportion to } \\
\text { dysarthria) }\end{array}$ \\
\hline \multirow[t]{3}{*}{11} & \multirow[t]{3}{*}{ Inattention } & 0 & No neglect or in coma \\
\hline & & 1 & $\begin{array}{l}\text { Partial neglect (visual, tactile, auditory, spatial, or personal inat- } \\
\text { tention or extinction to bilateral simultaneous stimulation in one } \\
\text { of the sensory modalities) }\end{array}$ \\
\hline & & 2 & $\begin{array}{l}\text { Complete-profound inattention to one or more modalities (does } \\
\text { not recognize own hand or orients to only one side of space) }\end{array}$ \\
\hline
\end{tabular}

Abbreviation: NIHSS, National Institute of Health Stroke Scale.

directly to radiology room, where members of stroke team evaluate and decide on eligibility for IVT and EVT. ER assessment and intervention can be done in CT room when ER is bypassed. All resuscitative equipment should be made available at all times.

\section{Neuroimaging}

Rapid imaging of the brain is the key to initiate IVT. NCCT is quick, possesses high sensitivity and specificity to detect intracranial hemorrhage (ICH), and can be done in critically ill patients without any delay. Stroke is a clinical diagnosis, and a normal NCCT does not rule out an AIS. NCCT can exclude alternate causes for neurological symptoms such as subdural hematoma, brain tumor, or other space occupying lesions. A NCCT of brain with no ICH or SAH usually is enough to decide eligibility for IVT in most cases. ${ }^{19}$ NCCT allows differentiation between ischemic stroke and intracerebral hemorrhage, and in the case of an ischemic stroke allows quantification of the extent of early ischemic changes by applying the Alberta Stroke Program Early CT Score (ASPECTS), a 10-point score that subtracts a point for each region of parenchymal hypoattenuation within the anterior circulation. ${ }^{20,21}$ Scan quality, training, and experience affect the reliability of ASPECTS (-Fig. 1). Automated software is now available to calculate ASPECT score. ${ }^{21}$ Lower scores are predictive of a poor functional outcome with an increased risk of intraparenchymal hemorrhage associated with thrombolysis. ${ }^{22,23}$

A normal looking CT brain implies that infarct has not set in and revascularization in this instance should result in better outcomes. Some of the early signs in CT are hypoattenuating brain tissue, obscuration of lentiform nucleus, dense MCA

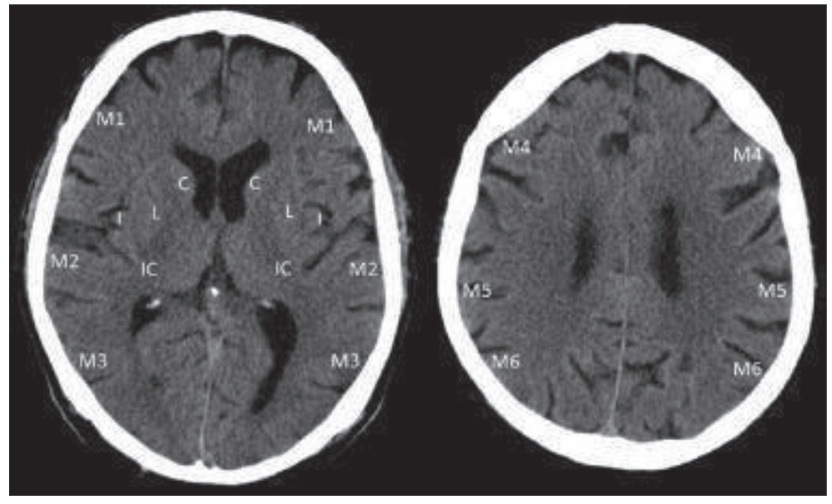

Fig. 1 ASPECT scoring system. Total Score 10. Each area of graywhite loss constitutes one deduction point. ASPECT, Alberta Stroke Program Early Computed Tomography; M1, frontal operculum; M2, anterior temporal lobe; M3, posterior temporal lobe; M4, anterior MCA; M5, lateral MCA; M6, posterior MCA; C, caudate; L, lentiform nucleus; I-insula; IC, internal capsule posterior limb; MCA, middle cerebral artery.

sign (implying LVO of ICA/MCA) ( - Fig. 2), insular ribbon sign, and loss of sulcal effacement. Frank hypodensities especially involving large area may be an established infarct and generally they are excluded from revascularization therapies.

IVT is usually initiated immediately after NCCT in the CT room. Once IVT is initiated for eligible patients after NCCT, a CT angiogram is performed for all patients. ${ }^{24}$ Patients with an LVO and eligible for EVT with LSN less than 6 hours are transferred to the neurointervention suite for EVT. Patients with LVO and LSN > 6 hours and up to 24 hours will undergo further imaging, either CT perfusion or magnetic resonance imaging (MRI) to check eligibility for EVT.25 


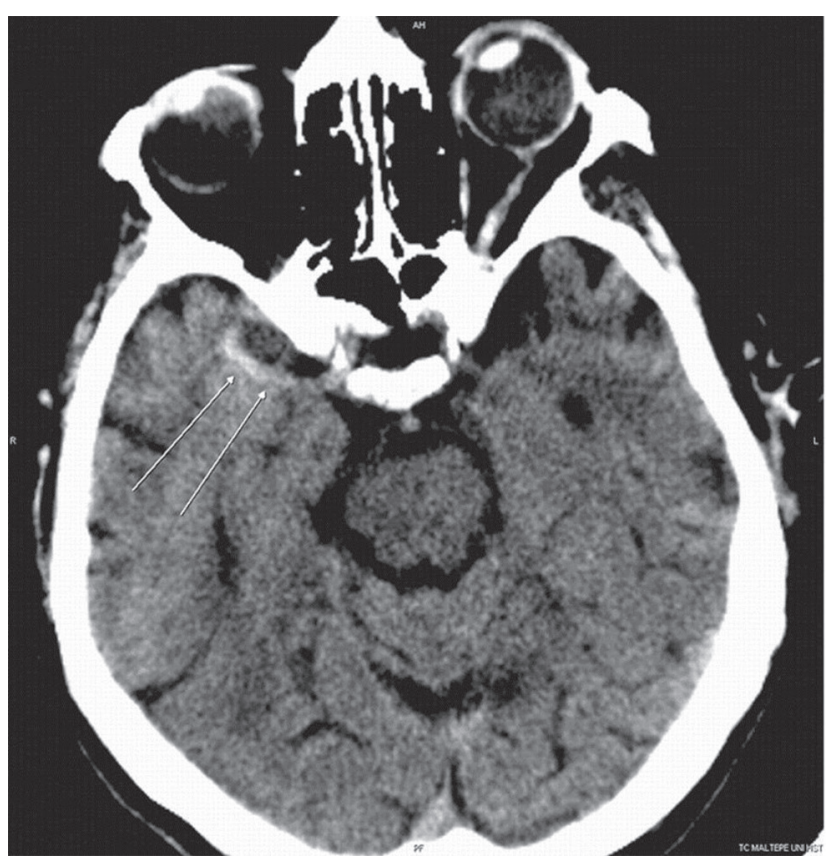

Fig. 2 Noncontrast computed tomography of brain showing right hyperdense middle cerebral artery (arrows).

CT angiography is used to identify proximal vessel occlusions as possible target lesions for EVT and should be a concurrent imaging study for patients with stroke ( - Fig. 3 ). Neurointerventionalists can plan an endovascular procedure with CT angiography information. ${ }^{26}$

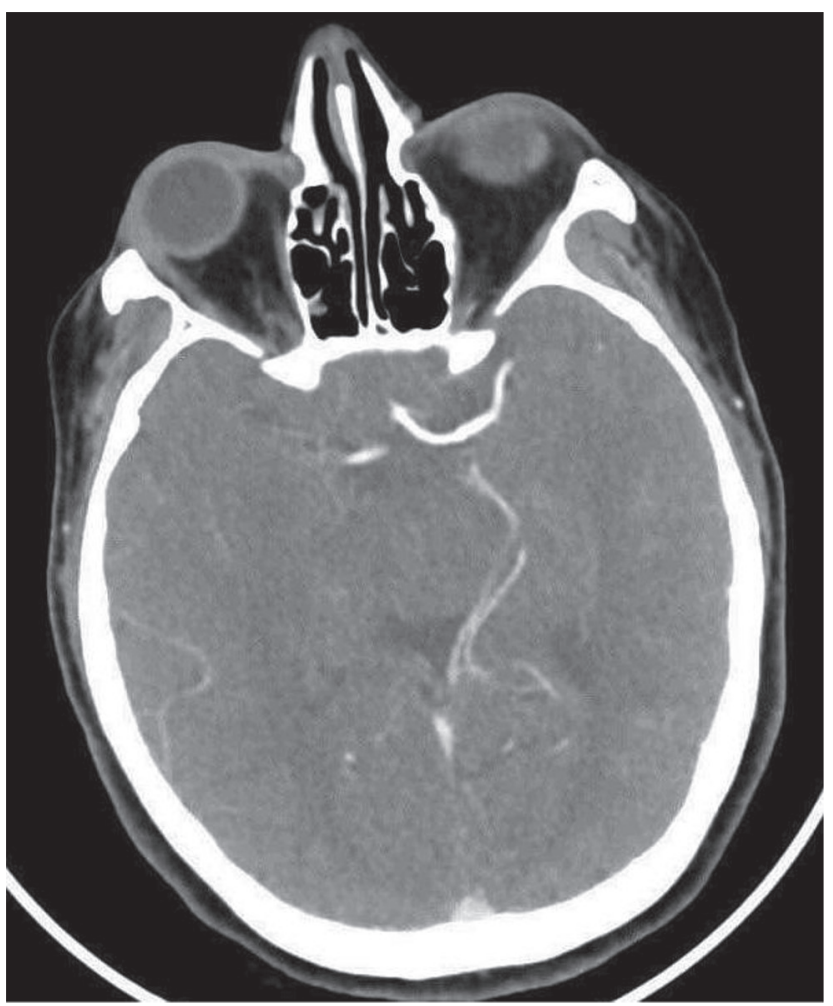

Fig. 3 Computed tomography angiography showing right middle cerebral artery occlusion.
MRI diffusion-weighted imaging and fluid-attenuated inversion recovery are more sensitive to detect ischemia/ infarction, but they are time consuming. DWI maps show early ischemic changes within minutes from stroke onset, and a correlating apparent diffusion coefficient map visualizes the extent of cytotoxic edema caused by brain ischemia. ${ }^{27}$ MRI is especially useful in detecting minor strokes and differentiating ischemic stroke from mimics in the setting of ischemic lesions of small volume ( - Fig. 4), multiple embolic lesions, and in posterior circulation strokes where the skull base creates bony artifacts on NCCT. Logistics and critical nature of illness make CT the preferred modality although MRI has been used as primary modality in some trials and centers to evaluate stroke.

Intensive efforts are underway to develop a practical and reliable way of assessing core and penumbra. With MRI, areas with diffusion-perfusion mismatch (i.e., DWI lesion within a larger area of perfusion-weighted imaging lesion) have been interpreted as penumbral tissue.

Time of flight MR angiography enables a flow-dependent visualization of the brain arteries without the need for a contrast agent. Susceptibility-weighted imaging allows for the detection of intracerebral hemorrhage with high sensitivity, and the detection of cerebral microbleeds not captured by NCCT, which might indicate underlying pathophysiology, such as cerebral amyloid angiopathy, and might be associated with an increased risk of intracranial hemorrhage after IVT. ${ }^{28}$ Specific MRI patterns of image acquisition and processing delay treatment initiation. The threshold for when sufficient information is available to make a correct therapeutic decision should be short. The

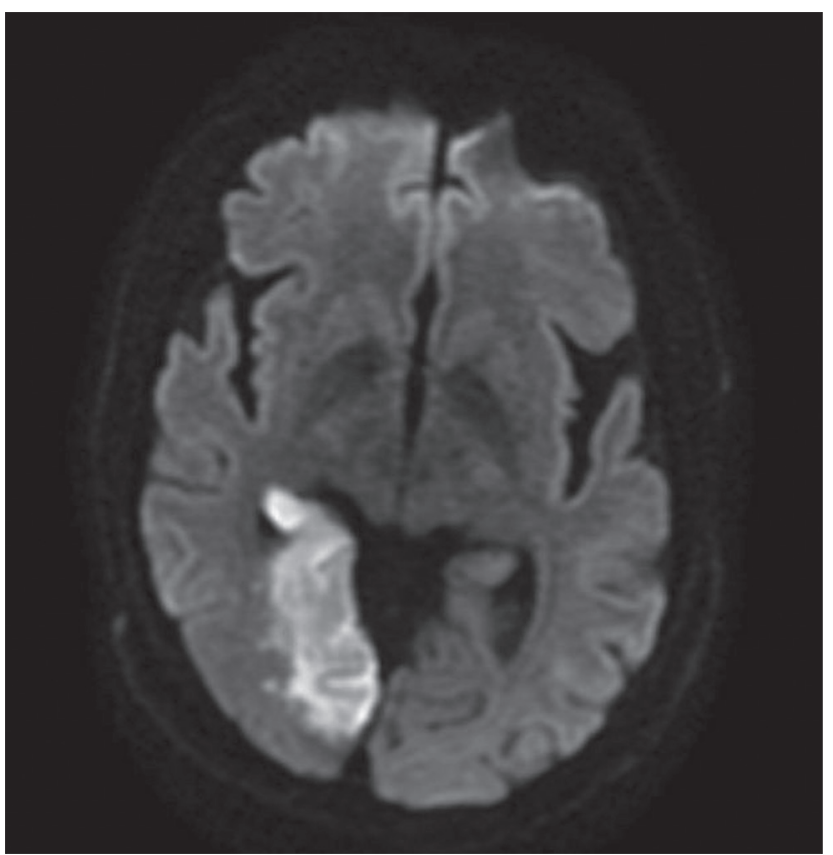

Fig. 4 Diffusion-weighted magnetic resonance imaging showing marked hyperintensity suggestive of acute ischemia in the right posterior cerebral artery territory. 
chance of poor outcome with treatment increases, while time passes with each additional test obtained. ${ }^{29}$

Many centers incorporate CT perfusion to assess mean transit time (MTT), CBF, cerebral blood volume, and other parameters to gain insight into the proportion and volume of tissue at risk of infarction. Quantitative perfusion thresholds are used to estimate core (tissue that is already irreversibly damaged), penumbra (tissue that is likely to infarct but salvageable with reperfusion and oligemia (tissue that is not threatened but might have reduced blood flow). A severe relative reduction in $\mathrm{CBF}$ of $<30 \%$ of normal brain indicates irreversible injury in several trials, including late window treatment trials. Automated software now allows timely postprocessing of CT perfusion functional maps that are robust to common artifacts, allowing rapid interpretation by the clinician ( - Fig. 5). However, care is required to avoid delaying treatment decisions because of the time taken to acquire, transfer, postprocess, and interpret CT perfusion data. ${ }^{29-32}$

\section{Mechanisms and Principles of Acute Ischemic Stroke Therapy}

The most effective treatment of AIS is timely reperfusion by either thrombolysis or thrombectomy. Reperfusion improves outcomes by reducing the volume of infarct. As time from initial stroke increases, the penumbra (viable but ischemic tissue) is quickly replaced by infarcted tissue (irreversibly lost brain tissue)..$^{33}$ Therefore, swift reperfusion preserves not only the penumbra tissue but also reduces the size of the final infarct core, thereby limiting the volume of damaged tissue and reducing disability from stroke.

\section{Intravenous Thrombolysis}

The National Institute of Neurological Disorders and Stroke (NINDS) tissue plasminogen activator (tPA) stroke trial is the landmark trial which leads to the licensing of alteplase in 3-hour window period of stroke. ${ }^{34}$ Subsequently, ECASS ${ }^{35}$ and ATLANTIS-Btrials ${ }^{36}$ evaluated the outcome within 6 hours of symptom onset and the post hoc analysis favored the earlier use is associated with improved outcome thus extending the window to 4.5 hours. The benefit of Alteplase in the 3 to 4.5-hour window has been reemphasized by the results of ECASS II trial. ${ }^{37}$ Though the largest trial of thrombolysis showed the improved functional outcome of thrombolysis within 6 hours, the benefit was more when treated within 3 hours. The pooled analysis of multiple trials including NINDS and ATLANTIS reported no outcome benefit of using Alteplase more than the 4.5-hour window. ${ }^{38}$ The benefit of low dose of alteplase was analyzed specifically in patients on prior antiplatelets, but ENCHANTED trial reported neutral outcome. Further trials are necessary to identify the benefit of low-dose alteplase. ${ }^{39}$ Other drugs such as desmoteplase and tenecteplase have also been studied. Studies reported variable outcomes with desmoteplase. Though NORTEST ${ }^{40}$ trial did not favor tenecteplase over alteplase, the EXTENDIA TNK trial showed that tenecteplase had higher incidence of reperfusion and better functional outcome compared to alteplase within the 4.5 -hour window. ${ }^{41}$ Tenecteplase might be considered as an alternative to alteplase in patients with minor neurological impairment and no major intracranial occlusion.

Thrombolysis within the 3-hour window and 3- to 4.5hour window is initiated as per eligibility criteria ( - Table 2$)^{35}$ If there are no absolute contraindications (-Table $\mathbf{3}$ ), one can proceed with thrombolysis after having considered the relative conditions. Successful management of hypertension ( - Table 4 ) is essential to administer EVT. Uncontrolled hypertension increases the risks of symptomatic ICH (sICH). Any BP > 185/110 mm Hg should be treated aggressively to target $<180 / 105$ mm Hg during and after IVT. Major complications associated with IVT include ICH, systemic hemorrhage, and angioedema, which have to be quickly recognized and treated (-Table 5).

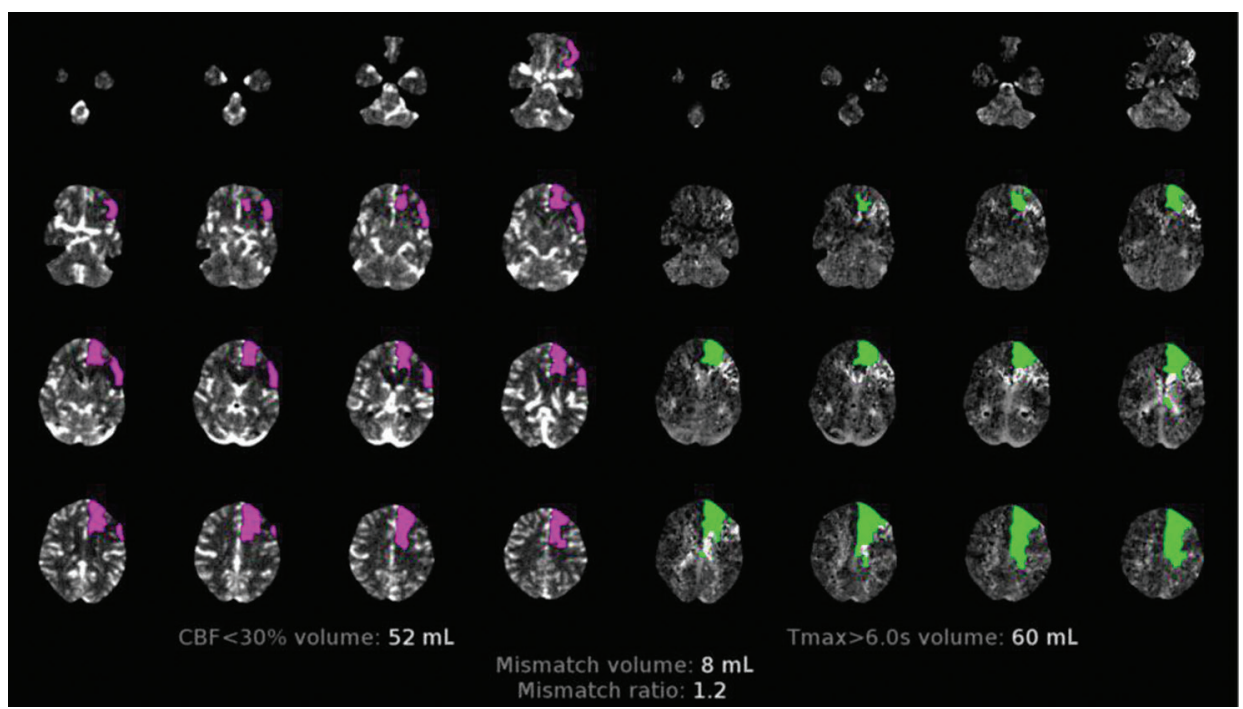

Fig. 5 Automated analysis of computed tomography perfusion showing cerebral blood flow $<30 \%$, volume $52 \mathrm{~mL}$; Tmax $>6.0 \mathrm{~s}$, volume 60 $\mathrm{mL}$; and mismatch volume $8 \mathrm{~mL}$ and mismatch ratio 1.2 . 
Table 2 Eligibility for IVT

\begin{tabular}{|l|}
\hline Time of onset of symptoms $<3 \mathrm{~h}$ \\
\hline - Age $\geq 18 \mathrm{y}$ \\
- $\mathrm{BP}<185 / 110 \mathrm{~mm} \mathrm{Hg}$ \\
- No Frank hypodensities in CT \\
\hline Time of onset of symptoms $3-4.5 \mathrm{~h}$ \\
\hline - All eligibility of $<3 \mathrm{~h}$ and \\
- Age $\leq 80 \mathrm{y}$ \\
- No H/O DM and prior stroke \\
- No H/O OAC \\
- $<1 / 3 \mathrm{HS} \leq 25$ \\
\hline
\end{tabular}

Abbreviations: BP, blood pressure; CBG, capillary blood glucose; CT, computed tomography; DM, diabetes mellitus; IVT, intravenous thrombolysis; MCA, middle cerebral artery; OAC, oral anticoagulant.

\section{IVT for Stroke with Unknown Time of Onset}

IV alteplase is generally not recommended in ischemic stroke patients, where the time of onset of symptoms is not clear. In a recent WAKE-UP clinical trial, patients with MRI DWI findings of an ischemic lesion without clearly visible FLAIR signal (indicates the onset of stroke to be less than 4.5 hours) are randomized to receive IVT versus placebo, and the authors found favorable functional outcome at 90 days with IVT. ${ }^{42}$

\section{Endovascular Treatment}

Endovascular treatment (EVT) with newer stent retrievers and aspiration devices has revolutionized the management of major stroke with LVO ( - Fig. 6). Clinical trials such as MR CLEAN, ${ }^{43}$ EXTEND-IA,${ }^{44}$ ESCAPE,${ }^{45}$ REVASCAT $^{46}$ SWIFT PRIME, ${ }^{47}$ THRACE, ${ }^{48}$ THERAPY, ${ }^{49}$ PISTE, ${ }^{50}$ and EASI ${ }^{51}$ reported positive outcomes in LVO strokes. Till recently EVT was offered only to

Table 3 Contraindications for IVT

- Time of onset of symptoms unclear

- Wake up stroke

- $\mathrm{ICH}$ in $\mathrm{CT} /$ history of ICH

- Clinical features strongly suggestive of SAH irrespective of CT negative for SAH

- Ischemic stroke/severe head injury/intracranial surgery/intraspinal surgery in the last $3 \mathrm{~m}$

- Structural GI malignancy or GI bleeding in the past 21 days

- Intracranial intra-axial neoplasm

- Aortic arch dissection

- Infective endocarditis

- Direct thrombin inhibitors/factor Xa inhibitors/GP IIa/IIIb receptor inhibitors/therapeutic LMWH in $24 \mathrm{~h}$

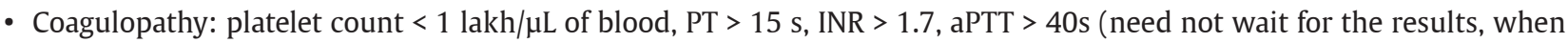
results are available and unfavorable STOP alteplase)

Abbreviations: aPTT, activated partial thromboplastin time; CT, computed tomography; GI, gastrointestinal; GP, glycoprotein; ICH, intracranial hemorrhage; INR, international normalized ratio; IVT, intravenous thrombolysis; LMWH, low-molecular-weight heparin; SAH, subarachnoid hemorrhage.

Table 4 Management of hypertension

- Measure BP and perform neurological assessments every 15 minutes during and after IV alteplase infusion for 2 hours, then every 30 minutes for 6 hours and then hourly until 24 hours

- Increase the frequency of BP measurements if SBP $>180 \mathrm{~mm} \mathrm{Hg}$ or if DBP is > $105 \mathrm{~mm} \mathrm{Hg}$; administer antihypertensive medications to maintain BP at or below these levels

- IV labetalol is the most commonly used and available antihypertensive. Adequate dose must be used and continuous infusion must be titrated to effect as BP bounce backs after bolus dose

- IV nicardipine and IV clevidipine are not available in India at present for usage. In the event of availability, both agents can be used

- If BP is not adequately controlled with IV labetalol, IV nimodipine, IV enalapril, or IV hydralazine whichever is available may be tried

Abbreviations: BP, blood pressure; DBP, diastolic blood pressure; IV, intravenous; SBP, systolic blood pressure.
Table 5 Management of symptomatic ICH after IVT

- Stop alteplase infusion

- Send CBC, PT (INR), aPTT, fibrinogen level, and type and cross-match

- Emergent head CT: confirm ICH

- Blood products: cryoprecipitate (includes factor VIII): $10 \mathrm{U}$ infused over 10-30 minutes (onset in $1 \mathrm{~h}$, peaks in $12 \mathrm{~h}$ ); additional dose for fibrinogen level of $<200 \mathrm{mg} / \mathrm{dL}$, consider 1 pooled platelet or SDP

- Antifibrinolytics: tranexamic acid $1000 \mathrm{mg}$ IV infused over 10 minutes OR $\varepsilon$-aminocaproic acid $4-5$ g over $1 \mathrm{~h}$, followed by $1 \mathrm{~g}$ IV until bleeding is controlled (peak onset in $3 \mathrm{~h}$ )

- Neurosurgery consultation

- Critical care management, including BP management, ICP, CPP, MAP, temperature, and glucose control

Abbreviations: aPTT, activated partial thromboplastin time; BP, blood pressure; CBC, complete blood count; CPP, cerebral perfusion pressure; $\mathrm{CT}$, computed tomography; ICH, intracranial hemorrhage; ICP, intracranial pressure; INR, international normalized ratio; IVT, intravenous thrombolysis; MAP, mean arterial pressure; SDP, single-donor platelet. 

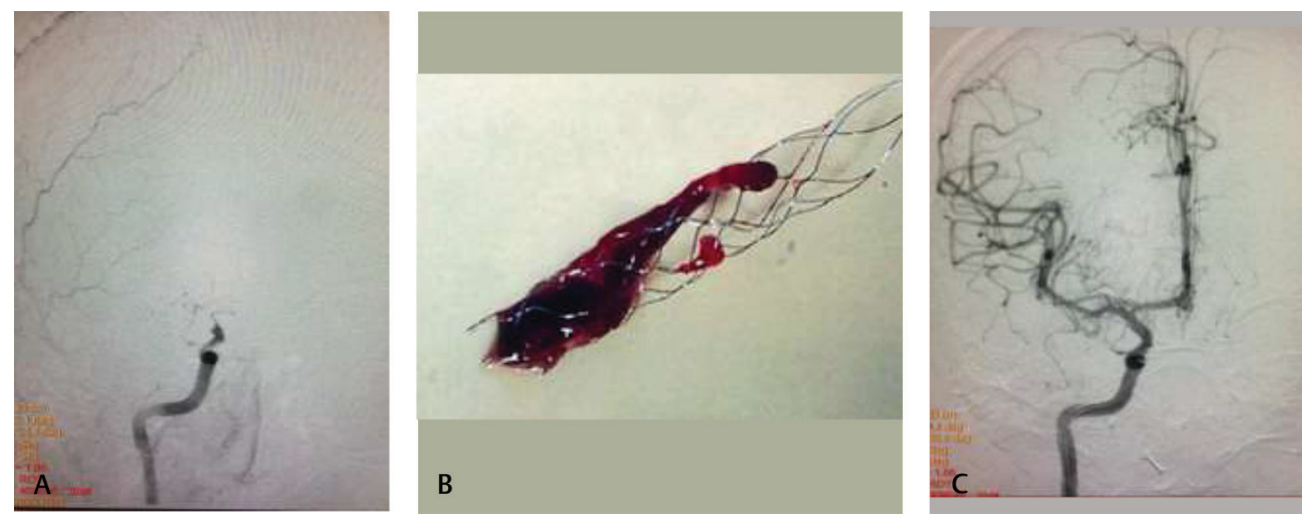

Fig. 6 (A) Right internal carotid artery occlusion. (B) Stent retriever with clot. (C) Revascularization with filling of right middle cerebral artery and anterior cerebral artery.

eligible patients presenting within 6 hours of symptom onset who satisfied the eligibility criteria. With advanced additional neuroimaging such as CT perfusion and MR perfusion, carefully selected patients outside the 6-hour window period up to 24 hours can be eligible for EVT (-Table 6). DAWN and DEFUSE- $3^{52}$ trails have reported positive outcomes in this subset of patients who present after 6 hours of symptom onset. Despite these late window studies, fast delivery of treatment remains crucial. The SWIFTPRIME trial reported that reperfusion within 150 minutes from symptom onset in the intervention arm led to a $91 \%$ estimated probability of functional independence, which decreased by $10 \%$ over the next hour and by $20 \%$ with every subsequent hour of delay. ${ }^{53}$

Thrombolysis in cerebral infarction (TICI) scale grading is used to access the success of EVT. TICI ranges from 0 (no reperfusion) to 3 (normal). Procedural success is usually defined as achieving TICI $2 \mathrm{~b}$ (antegrade partial perfusion of half or greater than the downstream ischemic territory) or TICI $3 .^{54}$

\section{Direct EVT versus Bridging Therapy in Stroke Patients Eligible for IVT}

The advantage of bridging therapy with IV thrombolysis before mechanical thrombectomy (MT) among patients with LVO has been studied. Fischer et al stated that immediate and direct MT (dMT) is equally effective and not inferior to bridging thrombolysis. ${ }^{55} \mathrm{~A}$ subsequent meta-analysis of 13 studies favored bridging thrombolysis over dMT patients. ${ }^{56}$ But this study has selection bias as they included both IVT eligible and ineligible patients. Further, in a pooled analysis of two stroke registries that included only patients who were eligible for IV thrombolysis, there was no difference in outcomes between the two groups. But with internal carotid artery occlusion, dMT had lower mortality. ${ }^{57}$ To exclude all selection bias, Kamal et al presented meta-analysis distinguishing between studies including dMT patients eligible for IVT and studies including dMT patients ineligible for IVT. Though dMT may offer comparable safety and efficacy as compared with IVT + MT, the results varied with less comparable groups. ${ }^{58}$ SWIFT DIRECT and MR CLEAN NO IV are the two RCTs in process and these studies will throw up some light on the debate on bridging therapy. We should always analyze for favorable factors, and the decision should be individualized.

\section{Bail Out Stents following Failed Anterior Circulation Thrombectomy}

Successful recanalization of emerging LVO is associated with favorable outcome. However, there is recanalization failure and 14 to $41 \%$ technical failure rate using stent retriever, balloon guide catheter, or a combination of techniques..$^{59}$ Studies showed good safety and recanalization rates with stent placement. Stent deployment maintains vessel patency and improves outcome but necessitates antiplatelet therapy and risk of sICH. Wareham et al in their analysis reported the rate of successful recanalization as $71 \%$ and favorable outcome in $43 \%$ of the patients. ${ }^{60}$ But the studies included were mostly retrospective and heterogenous. However, use of self-expandable stents as a bailout procedure appears to be a reasonable approach.

\section{Anesthesia for Endovascular Treatment}

Technique of anesthesia for EVT depends on multiple patient factors. Previously, a meta-analysis of nine retrospective studies suggested that general anesthesia was associated with worse functional outcomes and higher mortality rates. ${ }^{61}$ Recently, four prospective randomized controlled trials (RCTs) (GOLIATH, ${ }^{62}$ AnStoke, ${ }^{63}$ SIESTA, ${ }^{64}$ and EAST ${ }^{65}$ ) compared the use of general anesthesia versus conscious sedation for endovascular stroke treatment. They did not demonstrate any difference in neurological outcomes between the anesthesia types and found no delay in time to reperfusion in the general anesthesia group. Conscious sedation was associated with worse angiographic quality and more frequent patient movement, whereas general anesthesia was associated with higher rate of successful reperfusion. Hypotension during EVT was an independent predictor for poor neurological outcome. Hence, regardless of anesthesia technique, a strict protocol for aggressive management of intraprocedural systemic BP should be adopted during endovascular stroke treatment. ${ }^{66}$ 
Table 6 Eligibility for EVT

Standard eligibility (within 6 h)

- Pre-stroke mRS 0-1

- Occlusion of ICA/M1

- Age $\geq 18 \mathrm{y}$

- $\mathrm{NIHSS} \geq 6$

- ASPECTS $\geq 6$

- Groin puncture can be initiated within $6 \mathrm{~h}$

Late window eligibility

6-16 h (DEFUSE 3 criteria)

- Age 18-90 y

- NIHSS $\geq 6$

- Femoral puncture 6-16 h

- $\mathrm{mRS} \leq 2$

- CTA/MRA: ICA/MCA- M1 occlusion (OR) Tmax > 6 s perfusion deficit consistent with an ICA or MCA-M1 occlusion

- CTP/MRP:

- Ischemic core volume $<70 \mathrm{~mL}$

- Mismatch ratio $\geq 1.8$

- Mismatch volume $\geq 15 \mathrm{~mL}$ )

(OR)

- MRI DWI lesion volume $<25 \mathrm{~mL}$

6-24 h (DAWN criteria)

- Age $\geq 18 \mathrm{y}$

- Failed/contraindicated for alteplase

- $\mathrm{NIHSS} \geq 10$

- Pre-stroke mRS 0-1

- Groin puncture can happen in 6-24 h

- Anticipated life expectancy at least 6 months

- $<1 / 3$ rd MCA territory

- Intracranial ICA/MCA-M1 occlusion

- Clinical imaging mismatch

- Age $\geq 80$ y, NIHSS $\geq 10$ AND core $<21 \mathrm{~mL}$

- Age $<80 \mathrm{y}, \mathrm{NIHSS} \geq 10$ AND core $0-31 \mathrm{~mL}$

- Age $<80$ y, NIHSS $\geq 20$ AND core 31-51 mL

Abbreviations: ASPECTS, Alberta Stroke Program Early CT Score; CTA, computed tomography angiography; DWI, diffusion-weighted imaging; EVT, endovascular treatment; ICA, internal carotid artery; MCA, middle cerebral artery; MRA, magnetic resonance angiography; MRI, magnetic resonance imaging; mRS, modified Rankin Score; NIHSS, National Institutes of Health Stroke Scale.

\section{TIA and Minor Stroke}

The historical epidemiological definition differentiating transient ischemic attacks and ischemic stroke on the basis of the duration of their symptoms (less or more than 24 hours) is now outdated because duration does not accurately predict the pathology. MRI studies have shown that symptom duration greater than 1 hour is strongly associated with irreversible ischemia on diffusion-weighted MRI (DWI) and thus clinically defined transient ischemic attacks might not be transient on a tissue level. A transient ischemic attack is not a pathological entity itself but rather the mildest form on the spectrum of ischemic stroke syndrome presentations.

Fischer et al defined minor stroke as patients with NIHSS less than 3 as they had the best short-term and medium-term outcomes. ${ }^{67}$ All disabling strokes even though minor should be considered for reperfusion treatments. PRISM trial states that treatment with alteplase versus aspirin did not increase the likelihood of favorable functional outcome at 90 days. But the trial was prematurely terminated; hence, we cannot draw any conclusions. In the SITS-ISTR and GWTG registries, good functional outcomes, mortality, and risk of sICH were the same in mild stroke treated in 0 to 3 and 3 to 4.5 hours. ${ }^{68}$ Hence, treatment with IV alteplase may be reasonable in mild stroke presenting in the 3- to 4.5-hour window. ${ }^{69}$

Generally, an NIHSS of more than 5 points typically warrants thrombolysis in almost all cases; with NIHSS less than 5 , patients' premorbid quality of life and activities of daily living have to be taken into consideration to initiate thrombolysis. However, practice varies, with some clinicians consider thrombolysis for minor stroke as standard of care, while others consider it an unresolved research question. Patients with minor stroke are at risk of subsequent deterioration and disability. ${ }^{70}$ Establishing the balance between risk and benefit is the impetus for ongoing RCTs of thrombolysis in minor stroke. $^{71}$ 


\section{Malignant Infarction and Decompressive Craniectomy}

Osmotic therapy can beused for patients with clinical deterioration from cerebral swelling associated with cerebral infarction and is considered reasonable. In patients who develop symptoms of obstructive hydrocephalus from a cerebellar stroke, emergency ventriculostomy is a reasonable first step in the surgical management paradigm. ${ }^{72}$ Decompressive suboccipital craniectomy with dural expansion should be performed in patients with cerebellar infarction, causing neurological deterioration from brainstem compression despite maximal medical therapy. The outcome after cerebellar infarct can be good after suboccipital craniectomy. ${ }^{73}$

Malignant MCA infarction is a devastating event with substantial morbidity and mortality because of cerebral edema and raised intracranial pressure and risk of hemorrhagic transformation. Malignant MCA stroke is indicated by MCA territory stroke of $>50 \%$ on CT, perfusion deficit of $>66 \%$ on CT, and infarct volume $>82 \mathrm{~mL}$ within 6 hours of onset (on MRI). ${ }^{74-76}$ DECIMAL, ${ }^{77}$ DESTINY, ${ }^{78}$ and HAMLET ${ }^{79}$ trials and pooled analysis favored decompressive craniectomy over medical treatment in terms of mortality reduction, but functional outcome was not good. ${ }^{80}$ DESTINY II trial investigated in patients of age $>60$ years and reported mortality reduction but none of the survivors had good outcome. ${ }^{81}$ Hence, decompressive hemicraniectomy can be considered in patients $<60$ years of age, within 48 hours of stroke onset although outcomes are still likely to be poor. Decompressive craniectomy is not preferable in malignant MCA stroke patients aged > 60 years, as survivors will be severely disabled.

\section{Adjuvant Therapies}

\section{Antiplatelets}

For those treated with IV alteplase, aspirin administration is generally delayed until 24 hours. ${ }^{82}$ CHANCE trial favored dual antiplatelet therapy for minor stroke. ${ }^{83}$ POINT trial showed low risk of major ischemic events but a high risk of major hemorrhage in minor ischemic stroke or high-risk TIA who received a combination of clopidogrel and aspirin. ${ }^{84}$ Secondary analysis of POINT trial revealed that the risk of major hemorrhage was low and most were extracranial and treatable. Intracranial hemorrhages were rare..$^{85}$ It is recommended to give treatment for 21 days beginning within 24 hours and beneficial up to 90 days.

\section{Anticoagulation}

A systematic review by the Cochrane collaboration demonstrated that anticoagulation (with UFH, LMWH, heparinoids, oral anticoagulants, or thrombin inhibitors) did not decrease the odds of death or development of dependency from stroke. Although anticoagulants prevented pulmonary embolism, they also increased the risk of hemorrhage, leading to the conclusion that anticoagulation cannot be recommended for the treatment of AIS. ${ }^{86}$

\section{Hypothermia}

Though animal studies favor hypothermia as an excellent neuroprotective strategy, its benefit in patients with AIS has not been proven. Most trials including ICTUS $2^{87}$ and COOLIST $^{88}$ suggest that induction of hypothermia is associated with an increase in the risk of infection, including pneumonia. COOLIST study reported difficulty with induction and maintenance of hypothermia. They were able to achieve only temperature of $35^{\circ} \mathrm{C}$ with surface cooling. Further incidence of shivering was also higher with hypothermia.

\section{Neuroprotective Drugs}

Disrupted blood flow results in a cascade of molecular events leading to cell death. Energy stores deplete and membrane ion pumps malfunction. Excitatory neurotransmitters are released, and oxygen-free radicals are produced. Molecular mediators of this cascade have been tested as targets for drug therapy in animal models, but none has been successfully reduced to clinical practice. ${ }^{89}$

Trials of neuroprotective treatments in AIS have been negative. The FAST-MAG trial (Field Administration of Stroke Therapy-Magnesium) of hyperacute magnesium also reported no difference in outcome when compared with placebo in prehospital setting..$^{90}$ Hyperbaric oxygen was also found to be not useful in a recent Cochrane analysis.

\section{Sonothrombolysis}

Ultrasound waves can accelerate clot lysis through multiple mechanisms. Guidelines do not recommend the use of sonothrombolysis as an adjuvant therapy with IV thrombolysis, as there are no RCT data to support additional clinical benefit of sonothrombolysis. NOR-SASS trial did not report any significant difference neither in the functional outcome at 90 days nor in the rates of sICH. ${ }^{91}$

\section{Dysphagia}

Dysphagia, a common (37-78\%) complication of acute stroke, is a risk factor for aspiration pneumonia and is associated with higher mortality and worse patient outcomes. ${ }^{92}$ It is recommended to screen for dysphagia before the patient begins eating, drinking, or receiving oral medications to identify patients at increased risk of aspiration. Fiberoptic endoscopic evaluation of swallowing, video fluoroscopy are reasonable for those patients suspected of aspiration to verify the presence/absence of aspiration.

\section{Systems of Care}

Stroke is a quality initiative with a goal of door to needle time (DTN) in less than 60 minutes in at least $50 \%$ of eligible patients. The best practices include 11 care strategies to achieve faster DTN ( - Fig. 7): emergency medical services 


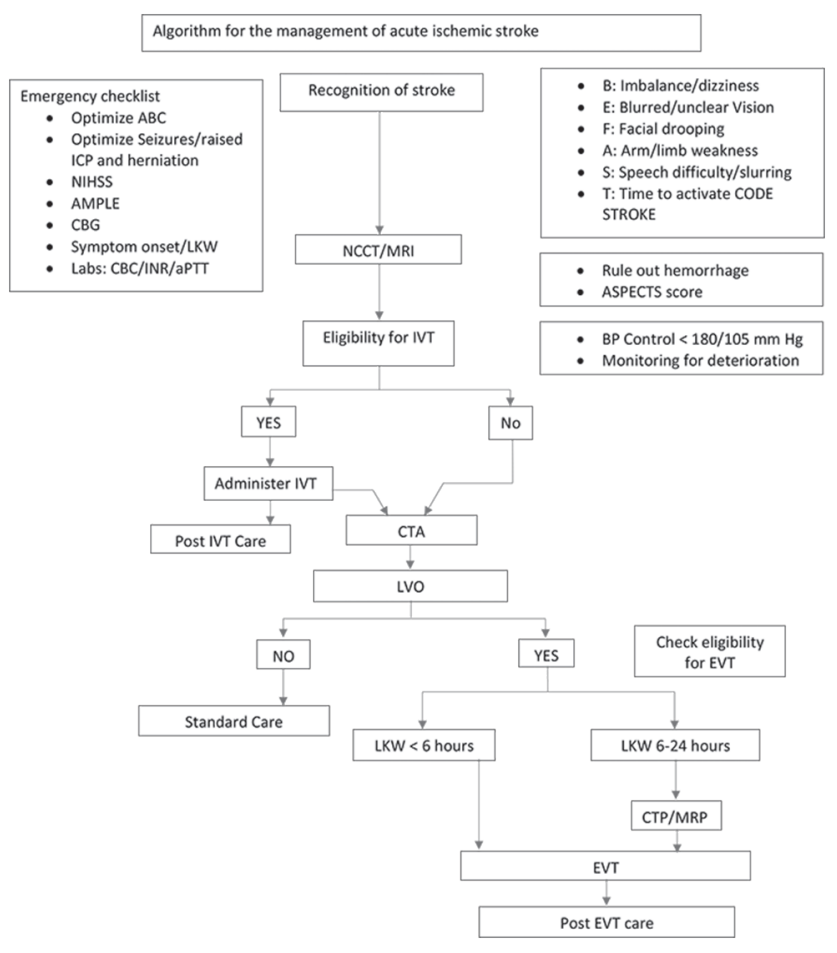

Fig. 7 Algorithm for the management of acute ischemic stroke. aPTT, activated partial thromboplastin time; ASPECTS, Alberta Stroke Program Early CT Score; BP, blood pressure; CBC, complete blood count; CBG, capillary blood glucose; CTA, computed tomography angiography; CTP, computed tomography perfusion; EVT, endovascular treatment; ICP, intracranial pressure; INR, international normalized ratio; IVT, intravenous thrombolysis; LKW, last known well; LVO, large vessel occlusion; MRI, magnetic resonance imaging; MRP, magnetic resonance perfusion; NCCT, noncontrast computed tomography; NIHSS, National Institutes of Health Stroke Scale.

pre-notification to hospitals about stroke patients, hospital-specific stroke protocols, a rapid stroke identification and notification system, a single-call stroke activation system, direct to CT protocol, rapid transportation to imaging, rapid interpretation of imaging, rapid protocols for laboratory testing, pre-mixing of recombinant-tPA (r-tPA) in patients with high likelihood of stroke, a team-based approach, and a prompt feedback system. These strategies reduced DTN from a mean of 74 minutes to 59 minutes. ${ }^{93}$ Now stroke phase II trial is ongoing with goal of DTN at least $75 \%$ of patients within 60 minutes of arrival and at least $50 \%$ of patients within 45 minutes of arrival.

Three features of protocol-pre-notification by ambulances, direct-to-CT imaging, and pre-mixing r-tPA-will help in achieving less DTN

\section{Telestroke}

Telestroke permits remote audiovisual connection between a stroke center (the "hub") and multiple community hospitals (the "spokes"). Telemedical consultation with a stroke neurologist remotely can reduce DTN times substantially at small hospitals. ${ }^{94}$ Transport to the nearest hospital is faster than to the "hub" hospital, potentially resulting in similar onset-totreatment times. ${ }^{95}$

\section{Mobile Stroke Units}

Apart from achieving earliest DTN, we should also aim to reduce the delay to hospital arrival. Programs have been developed to bring stroke physicians and r-tPA administration to the field in the form of a mobile stroke ambulance. These ambulances are equipped with a mobile CT scanner and point-of-care laboratory testing. In some programs, a stroke physician travels and some others have installed telemedicine equipment for remote interview and examination by a neurologist. 96,97

The prospective PHANTOM-S study compared conventional care to prehospital thrombolysis with r-tPA with an in-field emergency-trained vascular neurologist. Significantly more patients received $r-t P A$, and pre-hospital thrombolysis arm had a remarkably lower median onset-to-intervention time (50 vs. 105 minutes, $p<0.001$; PHANTOM-S). ${ }^{98}$ Mobile stroke units achieve better times even when compared to telestroke units.

\section{Conclusion}

The use of neuroimaging for patient selection and speed of diagnosis and delivery of treatment are the dominant themes of modern ischemic stroke care. Advances in technology have led to models of care to deliver r-tPA in a speedy and efficient manner, whether through pre-hospital triage via telephone, r-tPA administration via telemedicine, or actually administering r-tPA in the ambulance. These innovations have revolutionized AIS care from a disease with no treatments to one with multiple proven options.

\section{Conflict of Interest}

None declared.

\section{References}

1 The top 10 causes of death: factsheet, World Health Organization. 2017. Available at: https://www.who.int/news-room/factsheets/detail/the-top-10-causes-of-death. Accessed May 2019

2 Feigin VL, Nguyen G, Cercy K, et al; GBD 2016 Lifetime Risk of Stroke Collaborators. Global, regional, and country-specific lifetime risks of stroke, 1990 and 2016. N Engl J Med 2018; 379(25):2429-2437

3 World Stroke Organization Global Stroke Fact Sheet, Available at http://www.world-stroke.org. Accessed May 2019

4 Global Burden of Disease Stroke Statistics Worldwide for the year 2016. Available at: http://ghdx.healthdata.org/gbdresults-tool. Accessed May 2019

5 Benjamin EJ, Blaha MJ, Chiuve SE, et al; American Heart Association Statistics Committee and Stroke Statistics Subcommittee. Heart disease and stroke statistics-2017 update a report from the American Heart Association. Circulation 2017;135(10):e146-e603

6 Saver JL. Time is brain--quantified. Stroke 2006;37(1):263-266

7 Berglund A, Svensson L, Wahlgren N, et al. HASTA Collaborators. Face Arm Speech Time Test use in the prehospital setting, better in the ambulance than in the emergency medical communication center. Cerebrovasc Dis 2014;37:212-216

8 De Luca A, Giorgi Rossi P, Villa GF, et al. Stroke Group Italian Society PreHospital EMERGENCY SERVICES. The use of Cincinnati PrehospitalStroke Scale during telephone dispatch interview 
increases the accuracy in identifying stroke and transient ischemic attack symptoms. BMC Health Serv Res 2013;13:513

9 Katz BS, McMullan JT, Sucharew H, Adeoye O, Broderick JP. Design and validation of a prehospital scale to predict stroke severity: Cincinnati Prehospital Stroke Severity Scale. Stroke 2015;46(6):1508-1512

10 Ali Reza Noorian MD, Nerses Sanossian MD, Kristina Shkirkova BS, et al. Los Angeles motor scales to identify large vessel occlusion prehospital validation and comparison with other screens. Stroke AHA 2018;49:565-572

11 Jauch EC, Saver JL, Adams HP Jr, et al; American Heart Association Stroke Council; Council on Cardiovascular Nursing; Council on Peripheral Vascular Disease; Council on Clinical Cardiology. Guidelines for the early management of patients with acute ischemic stroke: a guideline for healthcare professionals from the American Heart Association/American Stroke Association. Stroke 2013;44(3):870-947

12 Higashida R, Alberts MJ, Alexander DN, et al; American Heart Association Advocacy Coordinating Committee. Interactions within stroke systems of care: a policy statement from the American Heart Association/American Stroke Association. Stroke 2013;44(10):2961-2984

13 Summers D, Leonard A, Wentworth D, et al; American Heart Association Council on Cardiovascular Nursing and the Stroke Council. Comprehensive overview of nursing and interdisciplinary care of the acute ischemic stroke patient: a scientific statement from the American Heart Association. Stroke 2009;40(8):2911-2944

14 Roffe C, Nevatte T, Sim J, et al; Stroke Oxygen Study Investigators and the Stroke OxygenStudy Collaborative Group. Effect of routine low-dose oxygen supplementation on death and disability in adults with acute stroke: the Stroke Oxygen Study Randomized Clinical Trial. JAMA 2017;318(12):1125-1135

15 Perini F, De Boni A, Marcon M, Bolgan I, Pellizzari M, Dionisio LD. Systolic blood pressure contributes to intracerebral haemorrhage after thrombolysis for ischemic stroke. J Neurol Sci 2010;297(1-2):52-54

16 Wohlfahrt P, Krajcoviechova A, Jozifova M, et al. Low blood pressure during the acute period of ischemic stroke is associated with decreased survival. J Hypertens 2015;33(2):339-345

17 Lin CB, Peterson ED, Smith EE, et al. Emergency medical service hospital prenotification is associated with improved evaluation and treatment of acute ischemic stroke. Circ Cardiovasc Qual Outcomes 2012;5(4):514-522

18 Lyden P, Raman R, Liu L, Emr M, Warren M, Marler J. National Institutes of Health Stroke Scale certification is reliable across multiple venues. Stroke 2009;40(7):2507-2511

19 Wardlaw JM, Seymour J, Cairns J, Keir S, Lewis S, Sandercock P. Immediate computed tomography scanning of acute stroke is cost-effective and improves quality of life. Stroke 2004;35(11):2477-2483

20 Barber PA, Demchuk AM, Zhang J, Buchan AM. Validity and reliability of a quantitative computed tomography score in predicting outcome of hyperacute stroke before thrombolytic therapy. ASPECTS Study Group. Alberta Stroke Programme Early CT Score. Lancet 2000;3559216 :1670-1674

21 Gupta AC, Schaefer PW, Chaudhry ZA, et al. Interobserver reliability of baseline noncontrast CT Alberta Stroke Program Early CT Score for intra-arterial stroke treatment selection. Am J Neuroradiol 2012;33(6):1046-1049

22 Dzialowski I, Hill MD, Coutts SB, et al. Extent of early ischemic changes on computed tomography (CT) before thrombolysis: prognostic value of the Alberta Stroke Program Early CT Score in ECASS II. Stroke 2006;37(4):973-978

23 Hill MD, Demchuk AM, Goyal M, et al; IMS3 Investigators. Alberta Stroke Program early computed tomography score to select patients for endovascular treatment:
Interventional Management of Stroke (IMS)-III Trial. Stroke 2014;45(2):444-449

24 Aulicky P, Mikulík R, Goldemund D, Reif M, Dufek M, Kubelka T. Safety of performing CT angiography in stroke patients treated with intravenous thrombolysis. J Neurol Neurosurg Psychiatry 2010;81(7):783-787

25 Chalela JA, Kidwell CS, Nentwich LM, et al. Magnetic resonance imaging and computed tomography in emergency assessment of patients with suspected acute stroke: a prospective comparison. Lancet 2007;369(9558):293-298

26 Yu AY, Zerna C, Assis Z, et al. Multiphase CT angiography increases detection of anterior circulation intracranial occlusion. Neurology 2016;87(6):609-616

27 Barber PA, Hill MD, Eliasziw M, et al; ASPECTS Study Group. Imaging of the brain in acute ischaemic stroke: comparison of computed tomography and magnetic resonance diffusion-weighted imaging. J Neurol Neurosurg Psychiatry 2005;76(11):1528-1533

28 Greenberg SM, Vernooij MW, Cordonnier C, et al; Microbleed Study Group. Cerebral microbleeds: a guide to detection and interpretation. Lancet Neurol 2009;8(2):165-174

29 d'Esterre CD, Boesen ME, Ahn SH, et al. Time dependent computed tomographic perfusion thresholds for patients with acute ischemic stroke. Stroke 2015;46(12):3390-3397

30 Bivard A, Kleinig T, Miteff F, et al. Ischemic core thresholds change with time to reperfusion: a case control study. Ann Neurol 2017;82(6):995-1003

31 Campbell BC, Christensen S, Levi CR, et al. Cerebral blood flow is the optimal CT perfusion parameter for assessing infarct core. Stroke 2011;42(12):3435-3440

32 Campbell BC, Yassi N, Ma H, et al. Imaging selection in ischemic stroke: feasibility of automated CT-perfusion analysis. Int J Stroke 2015;10(1):51-54

33 Nogueira RG, Jadhav AP, Haussen DC, et al; DAWN Trial Investigators. Thrombectomy 6 to 24 hours after stroke with a mismatch between deficit and infarct. N Engl J Med 2018;378(1):11-21

34 Berkhemer OA, Fransen PS, Beumer D, et al; MR CLEAN Investigators. A randomized trial of intraarterial treatment for acute ischemic stroke. N Engl J Med 2015;372(1):11-20

35 Demaerschalk BM, Kleindorfer DO, Adeoye OM, et al; American Heart Association Stroke Council and Council on Epidemiology and Prevention. Scientific rationale for the inclusion and exclusion criteria for intravenous alteplase in acute ischemic stroke. Stroke 2016;47(2):581-641

36 Hacke W, Kaste M, Bluhmki E, et al. Thrombolysis with alteplase 3-4.5 h after acute ischemic stroke. N Engl J Med 2008;359:1317-1329

37 The National Institute of Neurological Disorders and Stroke rt-PA Stroke Study Group. Tissue plasminogen activator for acute ischemic stroke. N Engl J Med 1995;333(24 ) :1581-1587

38 Hacke W, Kaste M, Fieschi C, et al; The European Cooperative Acute Stroke Study (ECASS). Intravenous thrombolysis with recombinant tissue plasminogen activator for acute hemispheric stroke. JAMA 1995;274(13):1017-1025

39 Robinson TG, Wang X, Arima $\mathrm{H}$, et al; ENCHANTED Investigators. Low-versus standard-dose alteplase in patients on prior antiplatelet therapy: the enchanted trial (enhanced control of hypertension and thrombolysis stroke study) Stroke 2017;48(7):1877-1883

40 Logallo N, Novotny V, Assmus J, et al. Tenecteplase versus alteplase for management of acute ischaemic stroke (NORTEST): a phase 3, randomised, open-label, blinded endpoint trial. Lancet Neurol 2017;16(10):781-788

41 Campbell BCV, Mitchell PJ, Churilov L, et al; EXTEND-IA TNK Investigators. Tenecteplase versus alteplase before thrombectomy for ischemic stroke. N Engl J Med 2018;378 (17):1573-1582 
42 Thomalla G, Simonsen CZ, Boutitie F, et al; WAKE-UP Investigators. MRI-guided thrombolysis for stroke with unknown time of onset. N Engl J Med 2018;379(7):611-622

43 Berkhemer OA, Fransen PS, Beumer D, et al; MR CLEAN Investigators. A randomized trial of intraarterial treatment for acute ischemic stroke. N Engl J Med 2015;372(1):11-20

44 Campbell BC, Mitchell PJ, Yan B, et al; EXTEND-IA investigators. A multicenter, randomized, controlled study to investigate EXtending the time for Thrombolysis in Emergency Neurological Deficits with Intra-Arterial therapy (EXTEND-IA) Int J Stroke 2014;9(1):126-132

45 Demchuk AM, Goyal M, Menon BK, et al; ESCAPE Trial Investigators. Endovascular treatment for small core and anterior circulation proximal occlusion with emphasis on minimizing CT to recanalization times (ESCAPE) trial: methodology. Int J Stroke 2015;10(3):429-438

46 Jovin TG, Chamorro A, Cobo E, et al; REVASCAT Trial Investigators. Thrombectomy within 8 hours after symptom onset in ischemic stroke. [REVASCAT] N Engl J Med 2015;372(24):2296-2306

47 Saver JL, Jahan R, Levy EI, et al; SWIFT Trialists. Solitaire flow restoration device versus the Merci Retriever in patients with acute ischaemic stroke (SWIFT): a randomised, parallel-group, non-inferiority trial. Lancet 2012;3809849:1241-1249

48 Bracard S, Ducrocq X, Mas JL, et al; THRACE investigators. Mechanical thrombectomy after intravenous alteplase versus alteplase alone after stroke (THRACE): a randomised controlled trial. Lancet Neurol 2016;15(11):1138-1147

49 Mocco J, Zaidat OO, von Kummer R, et al; THERAPY Trial Investigators*. Aspiration thrombectomy after intravenous alteplase versus intravenous alteplase alone. Stroke 2016;47(9):2331-2338

50 Muir KW, Ford GA, Messow CM, et al; PISTE Investigators. Endovascular therapy for acute ischaemic stroke: the Pragmatic Ischaemic Stroke Thrombectomy Evaluation (PISTE) randomised, controlled trial. J Neurol Neurosurg Psychiatry 2017;88(1):38-44

51 Khoury NN, Darsaut TE, Ghostine J, et al; EASI trial collaborators. Endovascular thrombectomy and medical therapy versus medical therapy alone in acute stroke: a randomized care trial. J Neuroradiol 2017;44(3):198-202

52 Albers GW, Lansberg MG, Kemp S, et al; . A multicenter randomized controlled trial of endovascular therapy following imaging evaluation for ischemic stroke (DEFUSE 3) Int J Stroke 2017;12(8):896-905

53 Goyal M, Jadhav AP, Bonafe A, et al; SWIFT PRIME investigators. Analysis of workflow and time to treatment and the effects on outcome in endovascular treatment of acute ischemic stroke: results from the swift prime randomized controlled trial. Radiology 2016;279(3):888-897

54 Yoo AJ, Simonsen CZ, Prabhakaran S, et al; Cerebral Angiographic Revascularization Grading Collaborators. Refining angiographic biomarkers of revascularization: improving outcome prediction after intra-arterial therapy. Stroke 2013;44(9):2509-2512

55 Ebinger M, Winter B, Wendt M, et al; STEMO Consortium. Effect of the use of ambulance-based thrombolysis on time to thrombolysis in acute ischemic stroke: a randomized clinical trial. JAMA 2014;311(16):1622-1631

56 Walter S, Kostopoulos P, Haass A, et al; . Diagnosis and treatment of patients with stroke in a mobile stroke unit versus in hospital: a randomised controlled trial. Lancet Neurol 2012;11(5):397-404

57 Hastrup S, Damgaard D, Johnsen SP, Andersen G. Prehospital acute stroke severity scale to predict large artery occlusion: design and comparison with other scales. Stroke 2016;47(7):1772-1776
58 Kamal N, Holodinsky JK, Stephenson C, et al; . Improving door-to-needle times for acute ischemic stroke: effect of rapid patient registration, moving directly to computed tomography, and giving alteplase at the computed tomography scanner. Circ Cardiovasc Qual Outcomes 2017;10(1)

59 Stroke Unit Trialists' Collaboration. Organised inpatient (stroke unit) care for stroke. Cochrane Database Syst Rev 2007;17(4):CD000197

60 Wareham J, Flood R, Phan K, et al. A systematic review and meta-analysis of observational evidence for the use of bailout self-expandable stents following failed anterior circulation stroke thrombectomy. J NeuroInterv Surg 2018. doi: 10.1136/ neurintsurg-2018-014459.

61 Brinjikji W, Murad MH, Rabinstein AA, Cloft HJ, Lanzino G, Kallmes DF. Conscious sedation versus general anesthesia during endovascular acute ischemic stroke treatment: a systematic review and meta-analysis. AJNR Am J Neuroradiol 2015;36(3):525-529

62 Simonsen CZ, Yoo AJ, Sørensen LH, et al; . Effect of general anesthesia and conscious sedation during endovascular therapy on infarct growth and clinical outcomes in acute ischemic stroke: a randomized clinical trial. JAMA Neurol 2018;75(4):470-477

63 Löwhagen Hendén P, Rentzos A, Karlsson JE, et al; . General anesthesia versus conscious sedation for endovascular treatment of acute ischemic stroke (The AnStroke Trial) Stroke 2017;48(6):1601-1607

64 Schönenberger S, Uhlmann L, Hacke W, et al. Effect of conscious sedation vs general anesthesia on early neurological improvement among patients with ischemic stroke undergoing endovascular thrombectomy: a randomized controlled trial. JAMA 2016;316(19):1986-1996

65 Peng Y, Wu Y, Huo X, et al; Endovascular Therapy for Acute Ischemic Stroke Trial (EAST) group. Outcomes of anesthesia selection in endovascular treatment of acute ischemic stroke. J Neurosurg Anesthesiol 2019;31(1):43-49

66 Talke PO, Sharma D, Heyer EJ, Bergese SD, Blackham KA, Stevens RD. Society for Neuroscience in Anesthesiology and Critical Care Expert consensus statement: anesthetic management of endovascular treatment for acute ischemic stroke*: endorsed by the Society of NeuroInterventional Surgery and the Neurocritical Care Society. J Neurosurg Anesthesiol 2014;26(2):95-108

67 Fischer U, Baumgartner A, Arnold M, et al. What is a minor stroke? Stroke 2010;41(4):661-666

68 Ahmed N, Wahlgren N, Grond M, et al; SITS investigators. Implementation and outcome of thrombolysis with alteplase 3-4.5 $\mathrm{h}$ after an acute stroke: an updated analysis from SITS-ISTR. Lancet Neurol 2010;9(9):866-874

69 Powers WJ, Rabinstein AA, Ackerson T, et al; American Heart Association Stroke Council. Guidelines for the Early management of patients with acute ischemic stroke: a guideline for healthcare professionals from the American Heart Association/ American Stroke Association. Stroke 2018;49(3):e46-e110

70 Coutts SB, Modi J, Patel SK, et al; . What causes disability after transient ischemic attack and minor stroke?: results from the CT and MRI in the triage of TIA and minor Cerebrovascular Events to Identify High Risk Patients (CATCH) Study. Stroke 2012;43(11):3018-3022

71 Bivard A, Huang X, Levi CR, et al. Tenecteplase in ischemic stroke offers improved recanalization: analysis of 2 trials. Neurology 2017;89(1):62-67

72 Raco A, Caroli E, Isidori A, Salvati M. Management of acute cerebellar infarction: one institution's experience. Neurosurgery 2003;53(5):1061-1065,discussion1065-1066

73 Agarwalla PK, Stapleton CJ, Ogilvy CS. Craniectomy in acute ischemic stroke. Neurosurgery 2014;74(Suppl 1):S151-S162 
74 Dittrich R, Kloska SP, Fischer T, et al. Accuracy of perfusion-CT in predicting malignant middle cerebral artery brain infarction. J Neurol 2008;255(6):896-902

75 Oppenheim C, Samson Y, Manaï R, et al. Prediction of malignant middle cerebral artery infarction by diffusion-weighted imaging. Stroke 2000;31(9):2175-2181

76 Kasner SE, Demchuk AM, Berrouschot J, et al. Predictors of fatal brain edema in massive hemispheric ischemic stroke. Stroke 2001;32(9):2117-2123

77 Vahedi K, Vicaut E, Mateo J, et al; DECIMAL Investigators. Sequential-design, multicenter, randomized, controlled trial of early decompressive craniectomy in malignant middle cerebral artery infarction (DECIMAL Trial) Stroke 2007;38 (9):2506-2517

78 Jüttler E, Schwab S, Schmiedek P, et al; DESTINY Study Group. Decompressive Surgery for the Treatment of Malignant Infarction of the Middle Cerebral Artery (DESTINY): a randomized, controlled trial. Stroke 2007;38(9):2518-2525

79 Hofmeijer J, Kappelle LJ, Algra A, Amelink GJ, van Gijn J, van der Worp HB; HAMLET investigators. Surgical decompression for space-occupying cerebral infarction (the Hemicraniectomy After Middle Cerebral Artery infarction with Life-threatening Edema Trial [HAMLET]): a multicentre, open, randomised trial. Lancet Neurol 2009;8(4):326-333

80 Vahedi K, Hofmeijer J, Juettler E, et al; DECIMAL, DESTINY, and HAMLET investigators. Early decompressive surgery in malignant infarction of the middle cerebral artery: a pooled analysis of three randomised controlled trials. Lancet Neurol 2007;6(3):215-222

81 Jüttler E, Unterberg A, Woitzik J, et al; DESTINY II Investigators. Hemicraniectomy in older patients with extensive middle-cerebral-artery stroke. N Engl J Med 2014;370(12):1091-1100

82 CAST. Randomised placebo-controlled trial of early aspirin use in 20,000 patients with acute ischaemic stroke: CAST (Chinese Acute Stroke Trial) Collaborative Group. Lancet 1997;349:1641-1649

83 Wang Y, Wang Y, Zhao X, et al; CHANCE Investigators. Clopidogrel with aspirin in acute minor stroke or transient ischemic attack. N Engl J Med 2013;369(1):11-19

84 Johnston SC, Easton JD, Farrant M, et al; Clinical Research Collaboration, Neurological Emergencies Treatment Trials Network, and the POINT Investigators. Clopidogrel and aspirin in acute ischemic stroke and high-risk TIA. N Engl J Med 2018;379(3):215-225

85 Tillman H, Johnston SC, Farrant M, et al. Risk for major hemorrhages in patients receiving clopidogrel and aspirin compared with aspirin alone after transient ischemic attack or minor ischemic stroke: a secondary analysis of the POINT randomized clinical trial. JAMA Neurol 2019;Epubaheadof print 29 April 2019 DOI 10.1001/jamaneurol.2019.0932

86 Gubitz G, Sandercock P, Counsell C. Anticoagulants for acute ischaemic stroke. Cochrane Database Syst Rev 2004; (3):CD000024

87 Lyden P, Hemmen T, Grotta J, et al; Collaborators. Results of the ICTuS 2 trial (Intravascular Cooling in the Treatment of Stroke 2) Stroke 2016;47(12):2888-2895

88 Geurts M, Petersson J, Brizzi M, et al. COOLIST (Cooling for Ischemic Stroke Trial): a multicenter, open, randomized, phase ii, clinical trial. Stroke 2017;48(1):219-221

89 Green AR. Why do neuroprotective drugs that are so promising in animals fail in the clinic? An industry perspective. Clin Exp Pharmacol Physiol 2002;29(11):1030-1034

90 Saver JL, Starkman S, Eckstein M, et al; FAST-MAG Investigators and Coordinators. Prehospital use of magnesium sulfate as neuroprotection in acute stroke. $\mathrm{N}$ Engl J Med 2015;372(6):528-536

91 Nacu A, Kvistad CE, Naess H, et al. NOR-SASS (Norwegian Sonothrombolysis in Acute Stroke Study): randomized controlled contrast-enhanced sonothrombolysis in an unselected acute ischemic stroke population. Stroke 2017;48(2):335-341

92 Joundi RA, Martino R, Saposnik G, Giannakeas V, Fang J, Kapral MK. Predictors and outcomes of dysphagia screening after acute ischemic stroke. Stroke 2017;48(4):900-906

93 Fonarow GC, Zhao X, Smith EE, et al. Door-to-needle times for tissue plasminogen activator administration and clinical outcomes in acute ischemic stroke before and after a quality improvement initiative. JAMA 2014;311(16):1632-1640

94 Heffner DL, Thirumala PD, Pokharna P, Chang YF, Wechsler L. Outcomes of spoke-retained telestroke patients versus hub-treated patients after intravenous thrombolysis: telestroke patient outcomes after thrombolysis. Stroke 2015;46(11):3161-3167

95 Sanders KA, Patel R, Kiely JM, Gwynn MW, Johnston LH. Improving telestroke treatment times in an expanding network of hospitals. J Stroke Cerebrovasc Dis 2016;25(2):288-291

96 Fassbender K, Walter S, Liu Y, et al. "Mobile stroke unit" for hyperacute stroke treatment. Stroke 2003;34(6):e44

97 Walter S, Kostpopoulos P, Haass A, et al. Bringing the hospital to the patient: first treatment of stroke patients at the emergency site. PLoS One 2010;5(10):e13758

98 Ebinger M, Kunz A, Wendt M, et al. Effects of golden hour thrombolysis: a Prehospital Acute Neurological Treatment and Optimization of Medical Care in Stroke (PHANTOM-S) substudy. JAMA Neurol 2015;72(1):25-30 